\title{
Pulse Electrodeposition of Sn-Ni-Fe Alloys and Deposit Characterisation for Li-ion Battery Electrode Applications
}

\author{
G. B. Lak, C. Chisholm, M. El-Sharif \\ School of Engineering and Built Environment, Glasgow Caledonian University, Glasgow, United Kingdom
}

Email address:

glak10@gcu.ac.uk (G. B. Lak), cuch@gcu.ac.uk (C. Chisholm), mel2@gcu.ac.uk (M. El-Sharif)

\section{To cite this article:}

G. B. Lak, C. Chisholm, M. El-Sharif. Pulse Electrodeposition of Sn-Ni-Fe Alloys and Deposit Characterisation for Li-ion Battery Electrode Applications. Advances in Materials. Special Issue: Advances in Electrodeposited Materials: Phase Formation, Structure and Properties. Vol. 4, No. 3-1, 2015, pp. 15-20. doi: 10.11648/j.am.s.2015040301.12

\begin{abstract}
Characterisation of Sn-Ni-Fe ternary alloy deposits obtained by pulse electrodeposition show that novel alloys of varying composition can be successfully deposited exhibiting amorphous structures using specific on/off pulse plating parameters for electrodeposition in combination with an electrolyte based on gluconate as a complexing agent. The deposits obtained exhibited high quality bright metallic surface morphologies combined with a distinct pronounced spherical/nodular grain structure across a range of average current densities. The influence of on/off period pulse current and the effect of the average current density on the surface morphology of the electrodeposited films were studied using Scanning Electron Microscopy (SEM). The cathode efficiency results obtained show that the pulse electrodeposition process chosen is significantly more efficient than the constant current electrodeposition. Results suggest that the substrate surface deformation condition and preparation are critically important in achieving a surface morphology suitable for an effective Sn-Ni-Fe alloy battery electrode. The alloy deposits with a morphology, which exhibits a high surface area per unit volume, are shown to be promising as an alternative anode material for lithium ion batteries.
\end{abstract}

Keywords: Pulse Electrodeposition, Amorphous Alloys, Sn-Ni-Fe Ternary Alloys, Thin Films, SEM, Li-ion Battery Electrodes, Substrate Surface Condition

\section{Introduction}

Li-ion batteries are one of the most important electrochemical power sources used to satisfy our existing and future energy needs. Substantial effort and investment are being directed toward accelerating the development of practical hybrid electric vehicles (HEVs) and plug-in hybrid electric vehicles (PHEVs), energy-efficient cargo ships, rail power, aerospace, power-grid applications and stationary storage of renewable energies such as solar and wind [1-3]. The Li-ion battery industry employs a wide variety of metals, metallic alloys and non-metallic materials with different structures as electrodes in various types of batteries. However, high cost, safety concerns, and the limited capacity of the graphite anodes (theoretical capacity of $372 \mathrm{mAh} / \mathrm{g}$ ) demand the development of alternative materials for the next generation of energy storage devices $[4,5]$. Tin-based alloys have attracted considerable interest as a more efficient alternative to pure tin anodes and traditional graphite based materials for Lithium-ion batteries. Tin has a higher specific theoretical capacity of $990 \mathrm{mAh} / \mathrm{g}$ [6] and currently appears to be one of the most promising candidates to replace graphite anode in lithium ion batteries.

Pulse electrodeposition methods have been extensively employed to obtain co-deposition of iron group alloys such as Fe-Ni [7-11] and to obtain good quality tin electrodeposition [12]. Pulse plating methods have also been shown to improve essential factors such as the electrodeposit surface morphology, the microstructure, appearance, corrosion resistance, hardness, residual stress and magnetization of iron-group alloy coatings compared to that achieved by using direct current techniques [7-11, 13, 14].

Amorphous alloy materials reported to show homogenous volume expansion during lithium insertion with no pulverization and high cycleability [15-19]. In earlier papers, the present authors $[20,21]$ reported that the pulse electrodeposition is an efficient method to deposit $\mathrm{Sn}-\mathrm{Ni}-\mathrm{Fe}$ ternary alloys exhibiting predominantly amorphous structures. Various pulse parameters were studied in order to determine their effect on the microstructure employing Conversion Electron Mossbauer Spectroscopy (CEMS) and X-ray 
Diffractometry. The results revealed that different on-time pulse currents facilitate the formation of a ferromagnetic or paramagnetic phase in the Sn-Ni-Fe alloy. The performance and the capacity of different samples as an anode in a Li-ion battery have been studied. [20].

The objective of the research studies reported in this paper is to extend the earlier results for electrodeposited $\mathrm{Sn}-\mathrm{Ni}-\mathrm{Fe}$ alloys [20, 22, 23] and discuss the characterisation of the surface morphology of the deposits, examine the effect of the $\mathrm{Cu}$ substrate surface condition on deposit morphology and report on the electrode performance of $\mathrm{Sn}-\mathrm{Ni}-\mathrm{Fe}$ alloy electrodeposits using specific on/off pulse electrodeposition conditions to achieve alloys with enhanced potential as an alternative anode materials for improved Li-ion batteries.

\section{Materials and Methods}

Copper substrate (as cold-rolled $99.97 \%$ purity, $0.175 \mathrm{~mm}$ thickness) test coupons with dimensions $5 \times 1 \mathrm{~cm}$ were used with an electroplated area of $2 \times 1 \mathrm{~cm}$ on either side. The coupons were degreased using acetone and prepared for electrodeposition as follows;

(1) used with additional electropolishing in phosphoric acid solution (66 wt. \%) at a constant current of $0.25 \mathrm{~A} / \mathrm{cm}^{2}$ for 2 minutes and thereafter rinsed in deionised water immediately prior to electrodeposition;

(2) used with additional immersing into the electropolishing solution for $30 \mathrm{~s}$ in order to remove any residual grease of the manufacturing process and thereafter rinsed in deionised water immediately prior to electrodeposition;

(3) used with additional grinding operations applying Grade 1200 sandpaper for 30 s to increase the surface area per unit volume and then rinsed in deionised water immediately prior to electrodeposition.

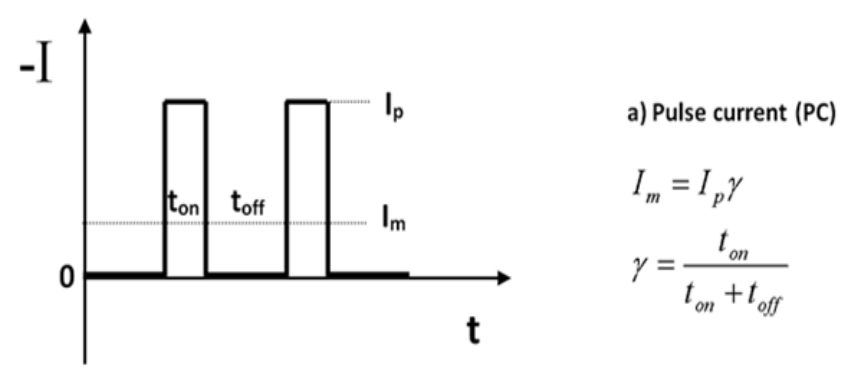

Figure 1. The square-wave pulse signal main parameters.

The electrolyte was prepared using an aqueous solution containing $0.3 \mathrm{M} \mathrm{NaCl}, 0.3 \mathrm{M} \mathrm{H}_{3} \mathrm{BO}_{3}, 0.02 \mathrm{M} \mathrm{SnSO}_{4}, 0.05 \mathrm{M}$ $\mathrm{NiSO}_{4}, 0.02 \mathrm{M} \mathrm{FeSO}$, $0.2 \mathrm{M}$ Sodium gluconate with $2 \mathrm{~g} / 1$ concentration of ascorbic acid used as an antioxidant and $0.1 \mathrm{~g} / 1$ peptone as a surfactant. The electrodeposition was carried out in a glass cylindrical cell at $20^{\circ} \mathrm{C}$ using a $\mathrm{pH}$ of 6.0 and agitation in combination with the use of different specific pulse current parameters which are described in Table 1. Fig1 illustrates the notations of the square-wave pulse signal parameters used. The cell anodes consisted of high density carbon, situated at $1 \mathrm{~cm}$ distance on either side of the copper cathode such that both sides of the cathode could be electroplated under similar current distribution conditions. Typically, three identical test samples were prepared for each set of deposition conditions.

The surface morphology was observed with a Zeiss EVO 50 scanning electron microscope and the elemental composition was determined using an EDAX EDS detector at $20 \mathrm{kV}$ and $\mathrm{I}_{\text {beam }}=40 \mathrm{pA}$.

A model Li-ion cell was used for testing the electrochemical performance. Lithium metal foils were used as the reference and counter electrodes. There was no separator in the cell. The electrolyte was $1 \mathrm{M} \mathrm{LiClO}_{4}$ dissolved in Ethylene Carbonate: Dimethyl Carbonate (1:1 by volume) solution. The cells were assembled in a glove box filled and purged with argon gas to maintain the environment at less than $10 \mathrm{ppm}$ of water. Cells were cycled at $20^{\circ} \mathrm{C}$ between $0.02 \mathrm{~V}$ and $1.5 \mathrm{~V}$ versus $\mathrm{Li} / \mathrm{Li}^{+}$at a constant current rate of $0.2 \mathrm{C}$, which can be calculated from the tin content using (1):

$$
\mathrm{I}_{\text {cycling }}=\mathrm{Sn}_{\text {theoreticalcapacity }} * \mathrm{Sn}_{\mathrm{wt} \%} * \mathrm{C}_{\text {rate }} * \Delta \mathrm{m}
$$

\section{Results and Discussion}

Table1 show typical results obtained using pulse deposition parameters alongside a typical result for constant current deposition (deposit 1). It can be seen for electrodeposits 3 to 6 obtained using $\mathrm{t}_{\mathrm{on}}=0.01 \mathrm{~s}$ and $\mathrm{t}_{\mathrm{off}}=0.49 \mathrm{~s}$ that the increase in the average current density causes the Fe content to decrease by about $16 \mathrm{wt} \%$, the Ni content to fluctuate around an average of $6 \mathrm{wt} \%$ and the Sn content to increase by about $15 \mathrm{wt} \%$. Higher Sn contents are important to ensure the specific theoretical capacity is as near to the $990 \mathrm{mAh} / \mathrm{g}$ as possible while at the same time ensuring that significant amounts of $\mathrm{Ni}$ and $\mathrm{Fe}$ are present to provide alloying which it was hoped would stabilise and minimise volume changes of the electrodeposited electrode during the lithiation-delithiation cycles which occur during the operational functioning of the Li-ion battery cell. By comparing electrodeposits 1 and 2 it can be seen that employing pulse electrodeposition $\left(\mathrm{t}_{\mathrm{on}}=0.1 \mathrm{~s}\right)$ leads to a significant increase in the Sn content of the alloy of around $13 \mathrm{wt} \%$ compared to constant current deposition.

The current efficiency for the constant current deposition and the pulse plating using $\mathrm{t}_{\text {on }}=0.1 \mathrm{~s}, \mathrm{t}_{\mathrm{off}}=0.9 \mathrm{~s}$ was found to be very similar at around $29 \%$ and $26 \%$, respectively, but for the electrodeposits obtained using $\mathrm{t}_{\text {on }}=0.01 \mathrm{~s}, \mathrm{t}_{\text {off }}=0.49 \mathrm{~s}$ the current efficiency shows a decrease with increasing $I_{p}$ and $I_{m}$ from a very high value of around $95 \%$ for deposit 3 to a very low value of around $4 \%$ for deposit 6 . This is due to the progressive increase in hydrogen reduction at the cathode with metallic nucleation and growth at the cathode surface being inhibited due to changes in the deposition kinetics, thus hindering the adsorption of the plating additives on to the cathode surface during deposition and resulting in an increased grain size. Hydrogen evolution may also increase mass transport and encourage grain growth rather than fresh nucleation leading to the corresponding compositional changes observed in the deposited alloys shown in Table 1. These changes to the nucleation and growth of the 
electrodeposits on the cathode are most probably also associated with changes to the surface morphologies of the final alloy deposits which could significantly affect the required properties of the electrodeposits being tested as an electrode in the Li-ion cell.

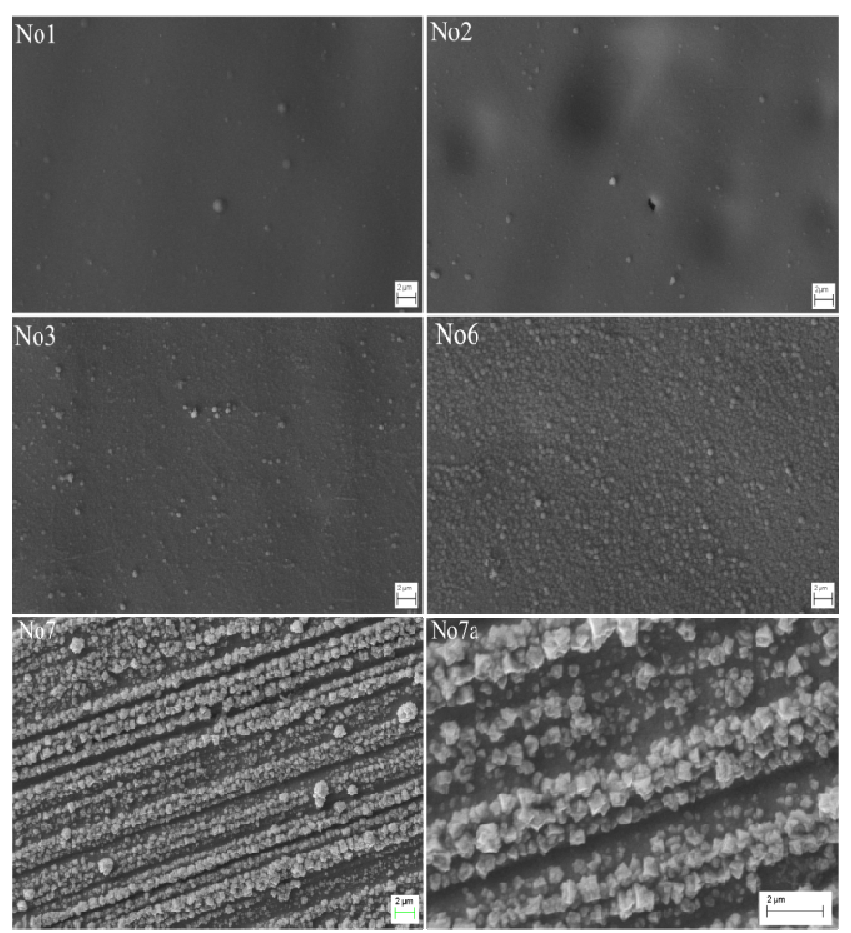

Figure 2. Surface morphology of the selected samples using SEM.

Fig2 shows typical SEM micrographs (magnification $\mathrm{x} 10,000)$ of the surface morphologies obtained for the pulse electrodeposited Sn-Ni-Fe alloys. In general the deposits exhibited surface morphologies which were compact and bright metallic in nature, had a fine grain distribution and were free of porosity and any form of surface cracking. The SEM micrographs show the influence on the surface morphology of the pulse current duty ratio $\left(\mathrm{t}_{\mathrm{on}} / \mathrm{t}_{\text {off }}\right)$ as well as the pulse current parameters $\left(I_{p}\right.$ and $\left.I_{m}\right)$. No significant differences in surface morphology are evident in the electrodeposits obtained at constant current deposition (deposit 1) and pulse electrodeposition (deposit 2). The similarity found for the microstructures is consistent with their deposition current efficiency being similar in value at current densities $7.27 \mathrm{~mA} / \mathrm{cm}^{2}$ and $6.99 \mathrm{~mA} / \mathrm{cm}^{2}$. Deposit 3, obtained using $\mathrm{t}_{\mathrm{on}}=0.01 \mathrm{~s}$, shows the initiation of a more distinctive spherical particle growth which probably correlates to the effect of a hundredfold decrease in the pulse time which in turn probably stimulates further spherical grain nucleation and subsequent growth. Comparing deposits 3 and 6, it can be seen that the fine particle size (average diameter of around 100nm) observed for deposit 3 changes with increasing average current density to give greater amounts of the more pronounced spherical/nodular particle distribution whereas for deposit 6 the average diameter of the particles was about $300 \mathrm{~nm}$. The change in growth is most probably due to the increased current density resulting change in the deposition kinetics at the diffusion layer leading to a more pronounced spherical/nodular grain structure.

Changing the substrate surface morphology prior to the alloy deposition process significantly changes the nucleation kinetics of the Sn-Ni-Fe alloy deposition process. The as cold-rolled copper foil surface for electrodeposit 7 was rinsed in the electropolishing solution to simply remove any residual grease and other detritus deriving from the prior industrial handling process. Pulse electrodeposition was then conducted on the as cold-rolled clean $\mathrm{Cu}$ foil substrate using $\mathrm{t}_{\mathrm{on}}=0.01 \mathrm{~s}$ and $\mathrm{t}_{\text {off }}=0.19 \mathrm{~s}$, and as can be seen alloy deposit 7 exhibits a significantly different morphology from the other samples shown in Fig2. Nucleation and subsequent growth has provided a much more pronounced spherical/nodular structure which is preferentially aligned with the deformation lines relating to what is probably the original direction of the industrial rolling process used to produce the $\mathrm{Cu}$ foil being used as the substrate material for the electrodeposition studies. The preferential growth alignment is most probably due to the observed variation in the nature of the cathode surface where nucleation and subsequent growth has clearly developed along the residual high surface energy deformation lines. As can be seen from Fig2 the SEM photomicrograph of deposit 7a, which is a higher magnification $(x 30,000)$ of deposit 7 , reveals the highly deformed micro-surface has yielded a surface structure with a large surface area per unit volume ratio which is more nodular than spherical in shape but nevertheless is a highly desirable deposit for the provision of a higher exchange current rate in Li-ion battery technology [24].

It appears that the formation of a more pronounced nodular particle distribution is facilitated by applying the short pulse time deposition $\left(t_{o n}=0.01 \mathrm{~s}\right)$ compared to the long pulse time deposition $\left(t_{o n}=0.1 \mathrm{~s}\right)$. Where $t_{\text {on }}=0.01 \mathrm{~s}$, the much shorter pulse deposition time probably stimulates greater nucleation of the alloy at the cathode with each pulse cycle thus generating a large number of growth centres leading to a more nodular particle distribution. This difference is not surprising as conditions at the catholyte-electrode interface could be expected to be significantly different with a tenfold difference in the on-pulse time. With higher current density, hydrogen obviously competes for reduction at the cathode as shown by a decreasing efficiency with increase in pulse current $\left(I_{p}\right)$. This may also contribute to the nucleation of the more pronounced nodular grain structure. The increase of the peak current $\left(\mathrm{I}_{\mathrm{p}}\right)$ causes the average diameter of the nodular particles to increase up to $300 \mathrm{~nm}$ for deposit 6 where the peak current $\left(\mathrm{I}_{\mathrm{p}}\right)$ has increased by a factor of four. The more pronounced nodular particle distribution generated using $\mathrm{t}_{\mathrm{on}}=0.01 \mathrm{~s}$ would thus tend to have a much greater surface area which would be an attractive surface morphology for an electrode in Li-ion batteries [24].

Previously reported results [20] with regards to $\mathrm{Sn}-\mathrm{Ni}-\mathrm{Fe}$ electrodeposits, galvanostatic charge-discharge test results, with similar alloy compositions to those reported for deposits 3 and 7 in Table1, are shown in Fig3. In this paper, these initial results are reproduced and extended. The earlier results showed [20], that the capacity after the $1^{\text {st }}$ cycle for an alloy 
deposit with $62 \mathrm{wt} \%$ of Sn gave a value of $530 \mathrm{mAh} / \mathrm{g}$ with a charge-discharge efficiency of $89 \%$. For an alloy deposit of 82 $\mathrm{wt} \%$ of $\mathrm{Sn}$, the capacity after the $1^{\text {st }}$ cycle was $755 \mathrm{mAh} / \mathrm{g}$ with a charge-discharge efficiency of $95 \%$. It was found that after 10 cycles the discharge capacity remained constant.

Table 1. Pulse deposition parameters and corresponding composition of Sn-Ni-Fe alloy deposits.

\begin{tabular}{|c|c|c|c|c|c|c|c|c|c|}
\hline \multirow{2}{*}{ No. } & \multicolumn{5}{|c|}{ Deposition parameters } & \multicolumn{3}{|c|}{ Elemental composition } & \multirow{2}{*}{$\begin{array}{l}\text { Current } \\
\text { efficiency }(\%)\end{array}$} \\
\hline & $t_{\text {on }}(s)$ & $t_{\text {off }}(s)$ & $I_{p}(\mathbf{m A})$ & $I_{m} /$ Area $\left(\mathrm{mA} / \mathrm{cm}^{2}\right)$ & Duration (s) & Sn Wt\% & Ni Wt\% & Fe Wt $\%$ & \\
\hline 1 & 1 & 0 & -10 & -7.27 & 600 & 50.1 & 12.9 & 37.0 & 29.4 \\
\hline 2 & 0.1 & 0.9 & -100 & -6.99 & 600 & 63.0 & 7.0 & 30.0 & 26.7 \\
\hline 3 & 0.01 & 0.49 & -100 & -1.67 & 600 & 63.0 & 6.5 & 30.5 & 95.4 \\
\hline 4 & 0.01 & 0.49 & -200 & -5.00 & 600 & 78.8 & 7.4 & 13.8 & 49.2 \\
\hline 5 & 0.01 & 0.49 & -300 & -6.00 & 600 & 79.7 & 5.4 & 14.9 & 23.3 \\
\hline 6 & 0.01 & 0.49 & -400 & -8.00 & 600 & 81.2 & 4.8 & 14.0 & 4.3 \\
\hline 7 & 0.01 & 0.19 & -100 & -2.94 & 900 & 82.4 & 3.1 & 14.5 & 97.0 \\
\hline
\end{tabular}

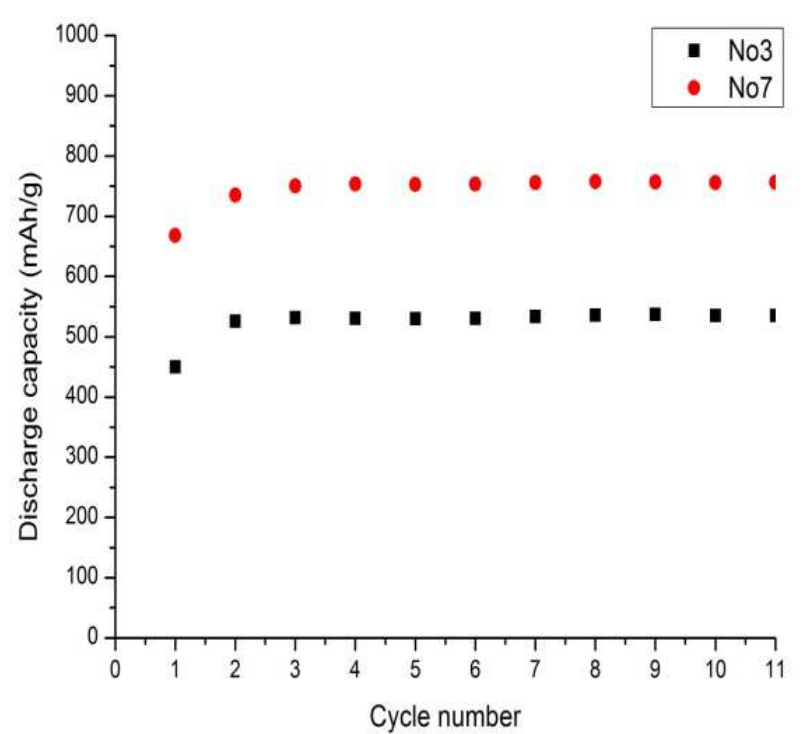

Figure 3. Galvanostatic charge-discharge tests of $\mathrm{Sn}-\mathrm{Ni}-\mathrm{Fe}$ samples as published earlier [20].

Compared with the carbon anodes, which have an average discharge capacity of $320 \mathrm{mAh} / \mathrm{g}$, these initial results suggested that pulse plated $\mathrm{Sn}-\mathrm{Ni}$-Fe deposits could give a two times higher specific capacity with a sustainable cycle life compared to carbon electrodes

Further studies were conducted to elucidate the role of the $\mathrm{Cu}$ surface substrate condition with regards to achieving deposits which showed good quality electrode properties for the Li-ion cell. From initial results it appeared that directional surface deformation could deliver deposits with a surface morphology which exhibited a high surface area per unit volume that is desirable for the electrode properties for Li-ion cells. On this basis various $\mathrm{Cu}$ substrate preparation methods were tested and the resulting deposits obtained were then measured in the model lithium cell using a series of similar Sn-Ni-Fe deposits in composition to deposit 3 (62 Wt\% of Sn) shown in Table1 and these results are shown in Fig4. The surface morphology of the as-rolled $\mathrm{Cu}$ foil substrate prepared by 2 minutes electropolishing resulted in a highly smooth surface which exhibited a high specular reflectivity and as can be seen from Fig4, this form of substrate surface preparation did not seem to facilitate the desired deposited structure as the charge-discharge cycle test resulted in a poor discharge capacity in conjunction with significantly poor cycleability for the deposited alloy electrode. It was anticipated that the addition of directional deformation marks to the electropolished surface to simulate the deformation obtained during the manufacture of the $\mathrm{Cu}$ foil would improve the electrode properties.

However, as can be seen in Fig4, the deposited electrode performance showed no improvement in properties when compared with the electropolished substrate. This may be due to the electropolishing process producing such a smooth surface that the deformation marks had little effect compared to the original deformation resulting from manufacture of the $\mathrm{Cu}$ foil which had probably been completely removed by electropolishing.

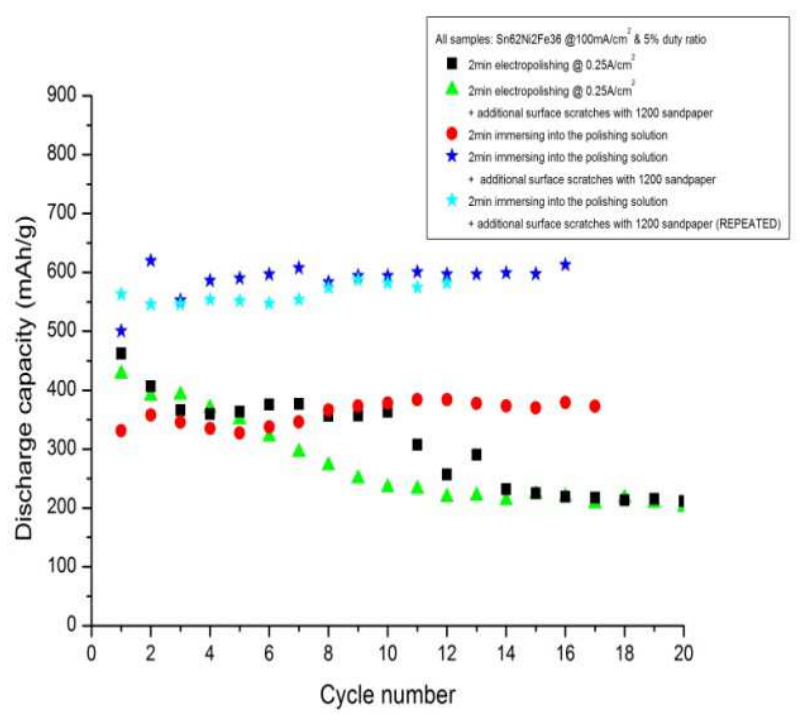

Figure 4. Galvanostatic charge-discharge tests and cycling efficiency of $\mathrm{Sn}-\mathrm{Ni}-\mathrm{Fe}$ samples with different substrate surface treatment (reproduced deposit 3 samples).

This suggested that it was important to retain the surface condition of the as manufactured copper foil which exhibited an aligned highly deformed micro-surface which only required immersion cleaning in the electropolishing solution to remove the organic contamination (grease) and other detritus associated with foil manufacture. The surface morphologies for the electropolished and immersion cleaned 
copper substrates are shown in Fig5 (A, B, C and D). It is clear that deposits prepared by immersion cleaning the copper in the electropolishing solution resulted in the retention of the original aligned deformed surface, which can be seen from Fig5C and 5D. It can be clearly seen that electropolishing removes this effect and this can be seen by comparing the higher magnification SEMs Fig5A and 5B. These micrographs clearly reveal the highly significant difference in the substrate surface which was obtained by simply immersion cleaning as compared to electro-polishing for 2 minutes. On the basis of these results it was anticipated that the further addition of aligned deformation marks to the surface of the as manufactured $\mathrm{Cu}$ foil could contribute to enhanced deposits in terms of electrode properties. When further directional deformation was added to the $\mathrm{Cu}$ foil substrate using 1200 grade sandpaper, it can be seen that highly significant improvements are achieved in the discharge capacity alongside a constant cycle life capability. This performance was verified by reproduction of the exact experimental conditions and the results were found to be similar as can be seen from Fig4. These results clearly demonstrate the importance of directional high energy surface roughness being generated on the $\mathrm{Cu}$ foil substrate as the discharge capacity has increased from around $350 \mathrm{mAh} / \mathrm{g}$ to around $600 \mathrm{mAh} / \mathrm{g}$ with corresponding constant cycle life capability. The theoretical discharge capacity for the alloy deposit with $62 \mathrm{wt} \%$ of $\mathrm{Sn}$ in the alloy gives a value of $614 \mathrm{mAh} / \mathrm{g}$ and as can be seen in Fig4, a discharge capacity of $600 \mathrm{mAh} / \mathrm{g}$ was achieved, which is almost equal to the theoretical capacity of the $\mathrm{Sn}$ content of the alloy combined with an extremely good cycle life.

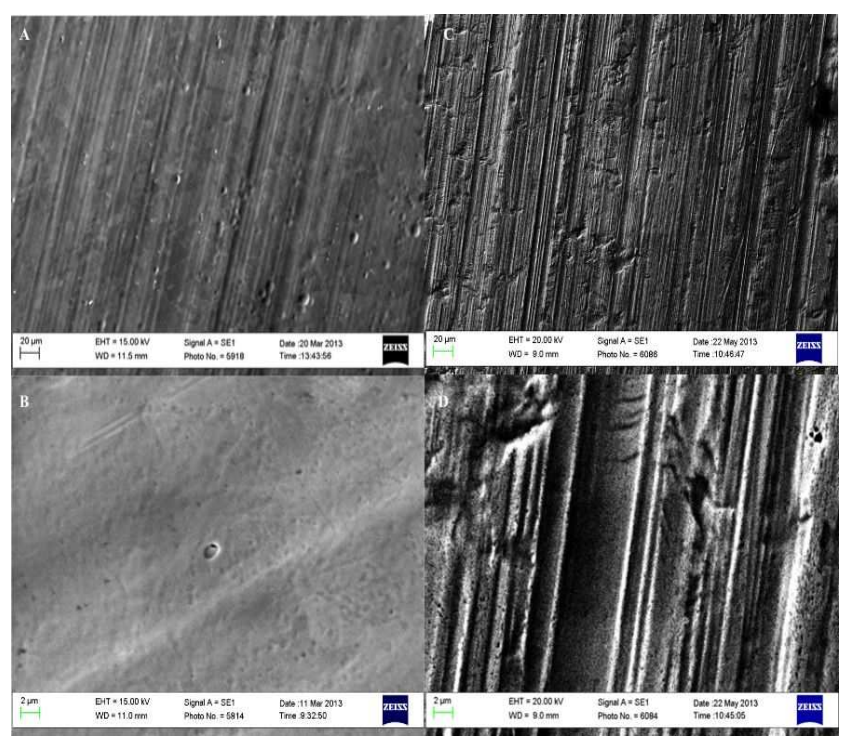

Figure 5. Surface morphology of the electropolished $(A \& B)$ and only immersed ( $C \& D)$ copper substrate using SEM.

The earlier published results [20] which were obtained using an alloy deposit with $82 \mathrm{wt} \%$ of $\mathrm{Sn}$ gave excellent electrode properties with a $\mathrm{Cu}$ substrate exhibiting directional deformation deriving from the manufacturing process. While this result was a useful indicator of the importance of the surface condition of the $\mathrm{Cu}$ foil substrate, it is to be expected that the manufactured foil could vary in surface roughness deformation from batch to batch and possibly within a batch, thus the resulting deposits could vary in electrode properties according to the levels of micro-deformation. The results obtained using immersion in the polishing solution to clean the substrate followed by controlled surface deformation show that the surface deformation condition of the substrate is critical in relation to the type of morphology grown by electrodeposition to form a deposit which supports delivery of a discharge capacity which is near to the theoretical capacity for the Sn content of the alloy alongside supporting the ability to give a constant cycle life.

\section{Conclusions}

- A range of novel amorphous $\mathrm{Sn}-\mathrm{Ni}-\mathrm{Fe}$ alloys were successfully deposited using a pulse plating process with various $\mathrm{t}_{\mathrm{on}} / \mathrm{t}_{\text {off }}$ pulse time ratios and peak currents.

- The pulse plated Sn-Ni-Fe alloys exhibiting a pronounced spherical/nodular grain structure show distinct potential to provide a new electrodeposited anode material for application in the Li ion battery. The capacity performance, charging efficiency and the cycle life obtained gave improved results to carbon anodes which are the main material being used at present for Li-Ion battery application.

- The results show that the surface condition of the substrate plays a fundamental role in the nature of the subsequent surface morphology developed during pulse electrodeposition and subsequently fundamentally affects the performance of the electrodeposited electrode in the Li-ion battery cell in terms of acceptable discharge capacity and cycle life.

- Further more detailed studies are now needed to produce controlled amounts of directional surface deformation similar to that found on the surface of the as manufactured $\mathrm{Cu}$ foil substrates to achieve alloy electrodeposits with carefully controlled surface morphologies which support discharge capacities near to the theoretical capacity for the Sn content of the alloys deposited alongside achieving a constant cycle life.

\section{References}

[1] H. Mousazadeh, A. Keyhani, A. Javadi, H. Mobli, K. Abrinia, A. Sharifi, "Evaluation of alternative battery technologies for a solar assist plug-in hybrid electric tractor" in Transportation Research Part D 15 (2010), pp. 507-512.

[2] P. Corbo, F. Migliardini, O. Veneri, "Lithium polymer batteries and proton exchange membrane fuel cells as energy sources in hydrogen electric vehicles" in Journal of Power Sources 195 (2010) pp. 7849-7854.

[3] I. A. G. Wilson, P. G. McGregor, P. J. Hall, "Energy storage in the UK electrical network: Estimation of the scale and review of technology options" in Energy Policy 38 (2010), pp. 4099-4106. 
[4] Thomas Mayer, Danny Kreyenberg, Jörg Wind, Frank Braun, Feasibility study of 2020 target costs for PEM fuel cells and lithium-ion batteries: A two-factor experience curve approach, International Journal of Hydrogen Energy, Volume 37, Issue 19, October 2012, Pages 14463-14474 .

[5] P.G. Balakrishnan, R. Ramesh, T. Prem Kumar, Safety mechanisms in lithium-ion batteries, Journal of Power Sources, Volume 155, Issue 2, 21 April 2006, Pages 401-414.

[6] A. H. Whitehead, J. M. Elliott, J. R. Owen, "Nanostructured tin for use as a negative electrode material in Li-ion batteries" in Journal of Power Sources 81-82 (1999), pp. 33-38 .

[7] B. N. Popov, Ken-Ming Yin, R. E. White, Galvanostatic Pulse and Pulse Reverse Plating of Nickel-Iron Alloys from Electrolytes Containing Organic Compounds on a Rotating Disk Electrode, J. Electrochem. Soc. 1993 140(5): 1321-1330.

[8] Peter T Tang, Pulse reversal plating of nickel and nickel alloys for microgalvanics, Electrochimica Acta, Volume 47, Issues 1-2, 1 September 2001, Pages 61-66.

[9] David L. Grimmett, Morton Schwartz, Ken Nobe, Pulsed Electrodeposition of Iron-Nickel Alloys, J. Electrochem. Soc. 1990 137(11): 3414-3418.

[10] David L. Grimmett, Morton Schwartz, Ken Nobe, A Comparison of DC and Pulsed Fe-Ni Alloy Deposits, J. Electrochem. Soc. 1993 140(4): 973-978.

[11] K.-M. Yin, S.-L. Jan, Current pulse plating of nickel-iron alloys on rotating disk electrodes, Surface and Coatings Technology, Volume 79, Issues 1-3, February 1996, Pages 252-262.

[12] Koichi Ui, Shinei Kikuchi, Yoshihiro Kadoma, Naoaki Kumagai, Shigeru Ito, Electrochemical characteristics of Sn film prepared by pulse electrodeposition method as negative electrode for lithium secondary batteries, Journal of Power Sources, Volume 189, Issue 1, 1 April 2009, Pages 224-229

[13] Jorge Vazquez-Arenas, Tanyakarn Treeratanaphitak, Mark Pritzker, Formation of $\mathrm{Co}-\mathrm{Ni}$ alloy coatings under direct current, pulse current and pulse-reverse plating conditions, Electrochimica Acta, Volume 62, 15 February 2012, Pages 63-72.

[14] Allen Bai, Chi-Chang Hu, Composition controlling of Co-Ni and $\mathrm{Fe}-\mathrm{Co}$ alloys using pulse-reverse electroplating through means of experimental strategies, Electrochimica Acta, Volume 50, Issue 6, 30 January 2005, Pages 1335-1345.

[15] L. Y. Beaulieu, T. D. Hatchard, A. Bonakdarpour, M. D. Fleischauer and J. R. Dahn, Reaction of Li with Alloy Thin
Films Studied by In Situ AFM, Journal of Electrochemical Society, Volume 150, Issue 11, 2003, A1457-A1464.

[16] L. Y. Beaulieu, K. W. Eberman, R. L. Turner, L. J. Krause and J. R. Dahn, Colossal Reversible Volume Changes in Lithium Alloys, Electrochemical and Solid-State Letters, Volume 4, Issue 9, 2001, A137-A140.

[17] T. D. Hatchard, J. M. Topple, M. D. Fleischauer and J. R. Dahn, Electrochemical Performance of SiAlSn Films Prepared by Combinatorial Sputtering, Electrochemical and Solid-State Letters, Volume 6, Issue 7, 2003, A129-A132.

[18] Z. H. Chen, V. Chevrier, L. Christensen, J. R. Dahn, Design of Amorphous Alloy Electrodes for Li-Ion Batteries A Big Challenge, Electrochemical and Solid State Letters, Volume 7, Issue 10, 2004, A310-A314.

[19] M. D. Fleischauer and J. R. Dahn, Combinatorial Investigations of the Si-Al-Mn System for Li-Ion Battery Applications, Journal of Electrochemical Society, Volume 151, Issue 8, 2004, A1216-A1221.

[20] G. B. Lak, E. Kuzmann, M. El-Sharif, C.U. Chisholm, S. Stichleutner, Z. Homonnay and L. Sziráki, Galvanostatic charge-discharge tests, 57Fe and 119Sn Mossbauer and XRD measurements on novel Sn-Ni-Fe electrodeposits, Hyperfine Interaction, Volume 218 (2013), Pages 145-150.

[21] S. Stichleutner, G. B. Lak, E. Kuzmann, C.U. Chisholm, M. El-Sharif., Z. Homonnay, L. Sziráki, Mössbauer And XRD Study of Pulse Plated Sn-Fe, Sn-Ni and Sn-Ni-Fe Electrodeposited Alloys, Hyperfine Interactions, 226(2014) $15-25$.

[22] L. Sziráki, E. Kuzmann, G.B. Lak, M. El-Sharif, C.U. Chisholm, S. Stichleutner, K. Havancsák, K. Zih-Perényi, Z. Homonnay, A. Vértes, Study of electrodeposition of amorphous $\mathrm{Sn}-\mathrm{Ni}-\mathrm{Fe}$ ternary alloys from a gluconate based electrolyte, Surface and Coatings Technology, Volume 211, 25 October 2012, Pages 184-187 .

[23] L. Sziráki, E. Kuzmann, M. El-Sharif, C.U. Chisholm, S. Stichleutner, G.B. Lak, K. Süvegh, E. Tatár, Z. Homonnay, A. Vértes, Electrodeposition of novel Sn-Ni-Fe ternary alloys with amorphous structure, Applied Surface Science, Volume 256, Issue 24, 1 October 2010, Pages 7713-7716.

[24] Jinpeng Yu, Zenghui Han, Xiaohong Hu, Hui Zhan, Yunhong Zhou, Xingjiang Liu, Solid-state synthesis of LiCoO2/LiCo0.99Ti0.01O2 composite as cathode material for lithium ion batteries, Journal of Power Sources, Volume 225, 1 March 2013, Pages 34-39. 